\title{
Comparative Study of Underground Pit Grain Storage System through Use of Different Lining Materials
}

\author{
Anbesse Girma ${ }^{1} \&$ Elias Ali $^{1}$ \\ ${ }^{1}$ Haramaya Institute of Technology, Department of Food Science and Postharvest Technology, Haramaya \\ University, Diredawa Ethiopia \\ Correspondence: Anbesse Girma, Department of Food Science and Postharvest Technology, Diredawa 138, \\ Ethiopia. E-mail: abutigirma@gmail.com
}

Received: November 26, 2019 Accepted: December 6, 2019 Online Published: December 12, 2019

The research is financed by Haramaya University through research grant office.

\begin{abstract}
Sorghum occupies highest area of cultivation in East and West Hararghe of Ethiopia. Farmers in the area are poor and do not afford an advanced storage systems. Hence, storage is done mainly in underground pit storage with different lining materials. This study was therefore aimed at evaluating those different lining materials in maintaining the sorghum quality. Four different lining materials which are commonly used by the farmers (mud/straw/cow dung mixture (3:3:1 ratio), plastic (thick rubberized canvas), chaff and cement) were used. Ten pits (duplicated), flask shaped with $1 \mathrm{~m}$ depth and $1 \mathrm{~m}$ diameter with a capacity of about two quintals $(200 \mathrm{~kg})$ were constructed. The finding in this comparative study is that, among all underlining materials, underground pit with plastic lining material was good barrier compared to all linings. Moisture migration to the grain increased in each month in all lining materials and the least was recorded in plastic lining. Germination capacity and thousand grain weight were reduced significantly in each material except plastic lining which showed the least change compared to the others. Fungi infestation was also increased in all underground pits with different lining materials. However, lower infestation was found in plastic and cement linings. Based on the quality measurements, plastic lining showed the least change in grain quality compared to the others. It can be concluded that, since the farmers can't afford advanced storage system, it can be recommended to use plastic lining material among the existing lining materials.
\end{abstract}

Keywords: pit storage, sorghum quality, lining materials, fungi infestation

\section{Introduction}

Sorghum is the third most important crop in Ethiopia, cultivated on one million hectares, and is the most important crop in drier, drought prone areas. Sorghum occupies $48 \%$ of cultivated land in East Harrarghe and $42 \%$ in West Harrarghe. Farmers in 'kola' or the lowland dry zone of East Harrarghe grow mainly long cycle maize and sorghum intercropped with groundnuts in the first cropping season, followed by short cycle varieties of maize and sorghum in the second season (McGuire 2005).

For long-term storage in Harrarghe, 70\% of the sorghum is stored in pits dug in sandy or gravel soils that are well drained (McGuire 2005; Dejene 2004). Pit stores are cheaper than above-ground storage and there is less damage due to insects, reduced risk of fire and theft. However, the high humidity and temperature in the unlined pits reduces seed viability (Dejene 2004).

Farmers in the central, northern, southern and western parts of Ethiopia commonly store their seeds and grains in the above-ground bin locally known as "gotera", which is made of bamboo sticks, wood and/or mud. However, the overwhelming majority of peasants (more than 70\%) in Harrarghe store their sorghum, and sometimes even maize, in the flask-shaped traditional underground storage pits of variable dimensions until it is consumed or sold when the grain market improves (Dejene 2004). The storage pits are mostly neither lined nor plastered with any material that would reduce moisture migration into the stored grain. The contact of the grain with wet pit walls often leads to moisture ingress into the inter-granular space elevating both the grain moisture content and the relative humidity inside the pit. 
It should be emphasized that underground pits can allow hermetic storage conditions where the decrease of oxygen and the increase of carbon dioxide concentration due to grain respiration make insects and rodents inactive. There are several methods, with different costs and impact that need to be tested and introduced to improve their efficiency. These include the lining of the pit walls with maize/sorghum sticks, plastic sheets, the digging of drainage systems around the pits and establishment of pits in elevated position. Therefore, this paper aims to evaluate those different lining materials on the quality of sorghum grain and recommendation of one with good efficiency.

\section{Materials and Methods}

\subsection{Study Area}

Haramaya University is found in east Hararghe which lies at 420 30'E longitude and $9026^{\prime} \mathrm{N}$ latitude. It is located $18 \mathrm{~km}$ away from Harar town and about $508 \mathrm{~km}$ east of the capital city, Addis Ababa. The mean annual rainfall is $492 \mathrm{~mm}$, which varies between 118 and $866 \mathrm{~mm}$. The experiment was conducted at Haramaya University located $1980 \mathrm{~m}$ above sea level.

\subsection{Construction of Underground Storage Pit}

Ten pits, flask shaped shallower but wider in cross section, with $1 \mathrm{~m}$ depth and $1 \mathrm{~m}$ diameter with a capacity of about 2 quintal sorghum with different lining materials were constructed. The different lining materials used were mud/straw/cow dung mixture in 3:3:1 ratio, plastic (thick rubberized canvas), chaff, cement lining and as a control room sack and bare pit storage were used. The sorghum required for the experiment was obtained from Haramaya Research Site (Rare).

\subsection{Sorghum Quality Assessment}

Grain sample, $1000 \mathrm{gm}$, was taken from each pit type with a double sleeve sampler at one month intervals for three months by opening the pits, inserting the spear from grain top to the bottom.

The grain moisture content, grain weight loss, molds (Aspergillus spp.) infestation, and germination capacity for the each pits of lining materials were analyzed.

\section{Moisture content}

The ratio of the difference between the initial weight and final weight to the initial weight was determined as percentage of moisture content (AOAC, 1995).

$$
M C_{w b}=1-\frac{\left(W_{d}\right)}{\left(W_{w}\right)} \times 100
$$

Where

$\mathrm{MC}_{\mathrm{wb}}$ : Moisture content (wet basis), $\mathrm{W}_{\mathrm{d}}$ : Weight of material after oven drying, $\mathrm{W}_{\mathrm{w}}$ : Weight of materials before oven drying

\section{Grain weight change}

The grain weight loss, due to different factors, was calculated using the thousand grain mass (TGM) method developed by Proctor \& Rowley (1983):

$$
\% \text { weight loss }=\frac{\left(M_{1}-M x\right)}{\left(M_{1}\right)} \times 100
$$

Where

$\mathrm{M} 1=$ thousand grain mass (TGM) at the beginning of the study and Mx = the TGM of stored grain for $\mathrm{x}$ duration

\section{Germination test}

Representative 100 sorghum kernels were steeped in $40 \mathrm{ml}$ of $0.75 \% \mathrm{H}_{2} \mathrm{O}_{2}$ in a clean Erlenmeyer flask of about $200 \mathrm{ml}$. The steeped kernels then placed in a clean place at room temperature $\left(23^{\circ} \mathrm{C}\right)$ for $48 \mathrm{hrs}$. After $48 \mathrm{hrs}$, the chitted kernels were drained counted and values were expressed as a percentage.

\section{Mold quality test}

Mold change with storage time was evaluated by taking grain samples from the pits. Samples of the grain to be examined were transferred to a fungal nutrient medium. After incubation, seed with fungi (Aspergillus spp.) showed a growth and counted. Then the percentage of seeds containing fungi (Aspergillus spp.) were calculated as 


$$
\% \text { infected seeds }=\frac{\text { (no. of infected seeds) }}{\text { total no. of seeds incubated }} \times 100
$$

\section{Experimental Setup}

All the pits lining materials were randomly distributed on the study site which was selected based on a number of factors such as drainage property and water table height. The data were arranged in factorial arrangement under Randomized Complete Block Design (RCBD). Analysis of quality parameters were done in replications. Analysis of variance was performed by using R-software. The sorghum selected for the study was a mixed variety obtained from rare research site of Haramaya University.

\section{Results and Discussions}

\subsection{Moisture Change}

Cereals go through different process of harvesting, drying, transportation and marketing before being consumed as food. Consequently, it involves microbiological contamination and insect infection due to microenvironment change (Abdullah et al., 2000). Low temperatures, relative humidity, and moisture contents are important for maintaining the quality of the stored produce (Anonymous, 2011). Moisture content is noted to be one of the most important factors that affect the quality of stored grains (Sisman and Ergin, 2011) and the most important factor determining seed longevity during storage (Qaisrani, 2000).

The moisture content was monitored to assess the variation and moisture levels of sorghum grain stored in the underground pit with different lining materials over the storage period. The grains before storage had an initial moisture content of $10.2 \%$. The moisture contents of sorghum under each lining materials during the storage period varies though not significantly different was observed $(P>0.05)$. The increased in moisture contents under plastic lining was low (around 20\% increment) compared to others whereas under bare lining material $(30.2 \%)$ and room storage (33.2\%) indicated high increment over the storage period. This study showed that, plastic lined pit form better barrier against diffusion of moisture from the walls and the bottom of the pit. It also controls grain soiling and moisture diffusion through the cracked pit wall (Laca et al., 2006).

The variation in moisture content under each lining materials could be due to changes in climatic factors such as the rainfall, temperature, relative humidity and sunshine and also due to respiration of grain and associated microorganisms. Moisture generation due to respiration of grain itself and insects can also raise moisture. It is generally accepted that climatic condition leads to physical changes in stored grain through the movement of moisture which leads to deterioration (Sawant et al., 2012). Sorghum stored using plastic lining material over the entire period exhibited high potential for long term storage. This might be due to its air-tight nature and protect water diffusion. Studies in many developed countries, comparing commercial and locally manufactured hermetic sealed storage systems with traditional storage systems showed that sealed systems prevent the uptake of moisture by the grain from the outside atmosphere, reduce the number of live insects, prolong the viability of seed, and maintain grain quality (Rickman and Aquino, 2004).

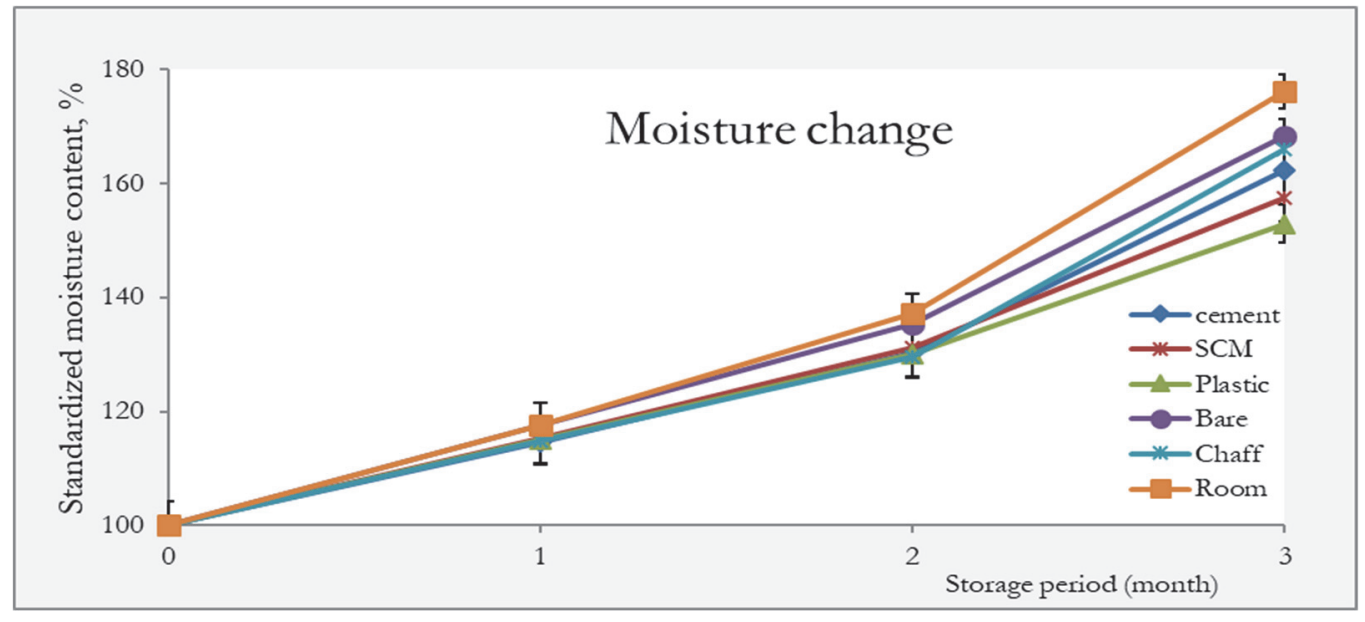

Figure 1. Change in moisture content of sorghum grain stored in underground pit storage with different lining materials (cement, room storage, chaff, bare, plastic and straw: cow-dung: mud (SCM) mix) for over three months of storage (Values are mean $\pm \mathrm{SE}$ ). 


\subsection{Germination Test}

Germination is the appearance of the first signs of growth, rise of the radical from the seed. It can be affected by factors such as grain moisture content, temperature, damages, fungi and insect infection. Grains retaining a high level of viability are likely to retain the other main qualities since the germination capacity is best measure of grain soundness (Fleurat-Lessard, 2002).

Germination test was carried out on the sorghum stored under various pit lining materials to assess how effective they are in maintaining the viability of the sorghum. The outcome showed a decline in germination capacity over the storage period in all lining materials (Fig. 2). The germination capacity of plastic lining, cement lining, room storage, chaff lining, bare and cow dung: mud: straw mixture lining at the end of the storage were $67.5 \%, 33 \%$, $21 \%, 10 \%, 9 \%$ and $6 \%$, respectively. Germination capacity showed a gradual decline under plastic and cement linings as compared to the others.

According to many literatures, the decline in germination capacity is due to many interactive factors such as insect infestation, fungal growth and change in storage micro environment mainly temperature, relative humidity and moisture (Black, 1970). There have been also reports by Sawant et al. (2012) that moisture content, temperature and relative humidity of storage structures had effects on the germination viability of seeds. Sorghum stored under plastic lining had the least viability losses followed by cement compared to the other lining materials $(P>0.05)$. Weinberg et al. (2008) stated that the germination percentage of grains stored in the sealed containers and noticed that the grain viability decreased over the storage period, and decreased as the moisture content increased.

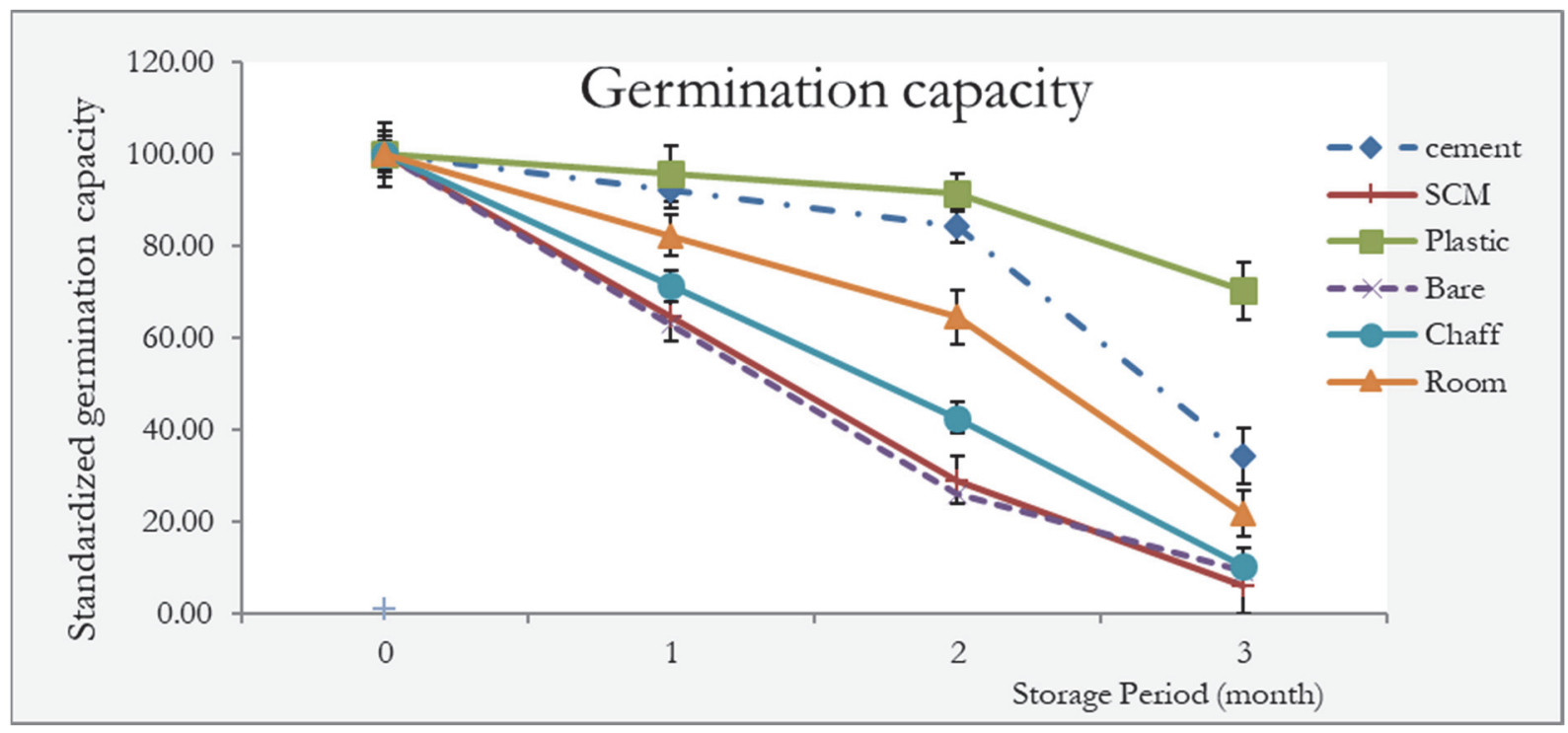

Figure 2. Germination capacity change of sorghum grain stored in underground storage with different lining materials: cement, room storage, chaff, bare, plastic, straw: cow-dung: mud (SCM) mix over three months

(Values are mean $\pm \mathrm{SE}$ )

\subsection{Thousand Kernel Weight}

The sorghum grain before storage had thousand seed weight of $39.47 \mathrm{~g}$. The thousand seed weight of sorghum stored in underground pit storages with pit linings of cement, plastic, cow dung: mud: straw mixtures, chaff, bare and room storage were dropped to $33.3 \mathrm{~g}, 34.20 \mathrm{~g}, 30.95 \mathrm{~g}, 35.0 \mathrm{~g}, 30.55 \mathrm{~g}$ and $29.00 \mathrm{~g}$, respectively during the third month of the storage period. The rate of weight loss in underground pit storages with pit linings of cement and plastic was low and high for other lining materials.

As indicated in the graph below (figure 3), thousand kernels weight was high for plastic and cement linings at the end of storage period. The loss in weight observed in all linings could primarily be due to fungi growth and moisture increment which might leads to higher respiration (see Fig. 1). The weight loss is relatively minimal in plastic lining as it had good potential in preventing moisture ingression. Aboagye et al. (2017) indicated that grain storages maintain loss of weight through preventing moisture ingression. 


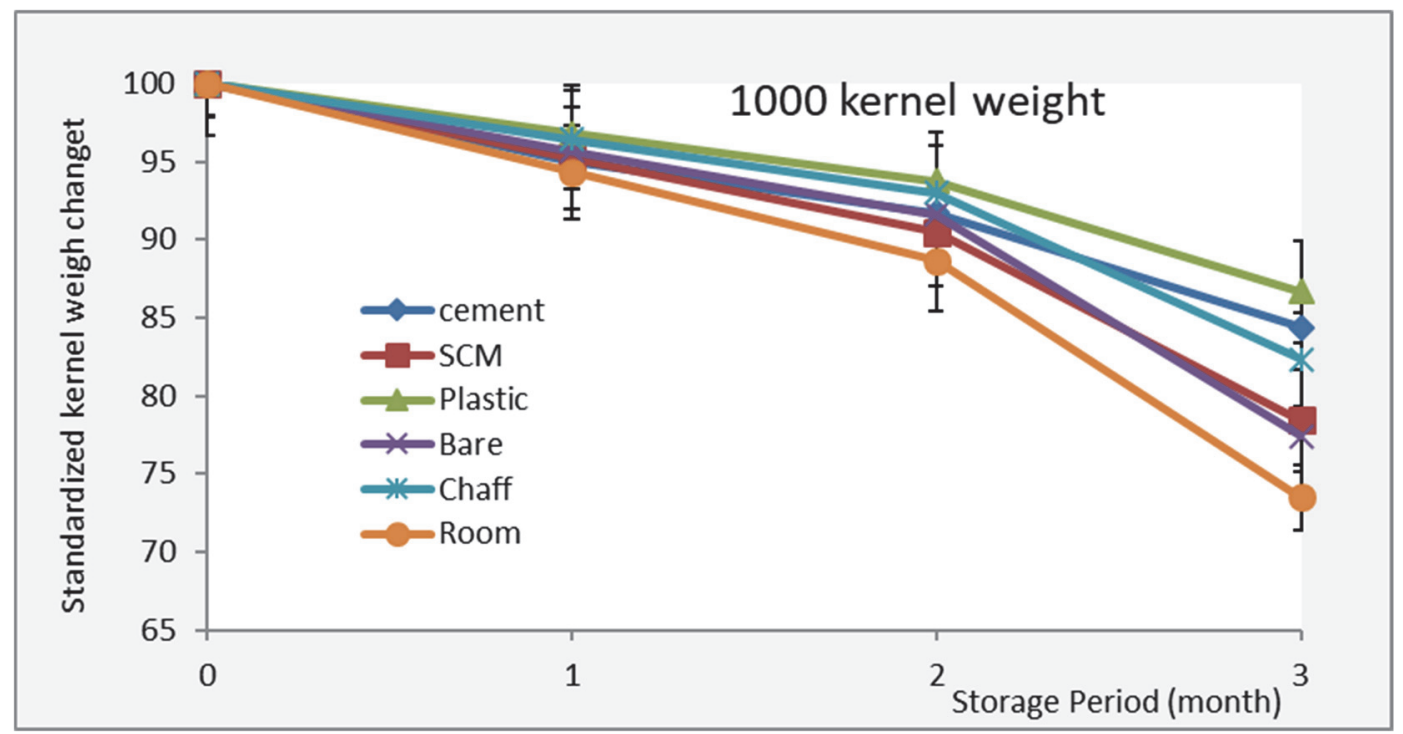

Figure 3. Thousand kernel weight change of sorghum grain stored in underground storage with different lining materials (cement, room storage, chaff, bare, plastic and straw: cow-dung: mud (SCM) mix) for over three months (Values are mean $\pm \mathrm{SE}$ )

\subsection{Fungi Infestation}

Microbial growth in stored grain is common especially fungi which infect agricultural crops both in the field and in storage. Agnieszka et al. (2013) reviewed that the variety of fungi which is common in stored grain are Fusarium, Cephalosporium, Alternaria, Cladosporium, and asperggillusspecies such as A. flavus, A. glaucus, A. niger, and A. ochraceus. Proper storage that can reduce moisture ingression and control the temperature helps to keep the grains for longer period.

Six lining materials were tested for the most common storage fungi, asperggillusspecies, and infected seeds were counted on each month (Fig. 4). At the beginning, the sorghum were tested for fungi, 7\% infection level, and used for all storage types. Rate of infection, as it can be seen from the graph, was gradual in plastic and cement lining material compared to the others. Room and bare underground storage techniques were the most worst where percentages of infected seeds reach up to $45 \%$ at the end of the third month indicating high rate of infection.

According to a review (Dorn et al., 2013), among most determinant factors for mould growth, moisture is the principal factor. The grain moisture increment during storage (see Fig. 1) could be the cause for high rate of mould (Aspergillus spp.) growth in all pit linings except the plastic and cement which showed marginally lower growth (see Fig. 4). Microbial, such as fungal, infestation furthermore, can cause grain discoloration, change its chemical characteristics and germination loses (Agnieszka et al., 2013). 


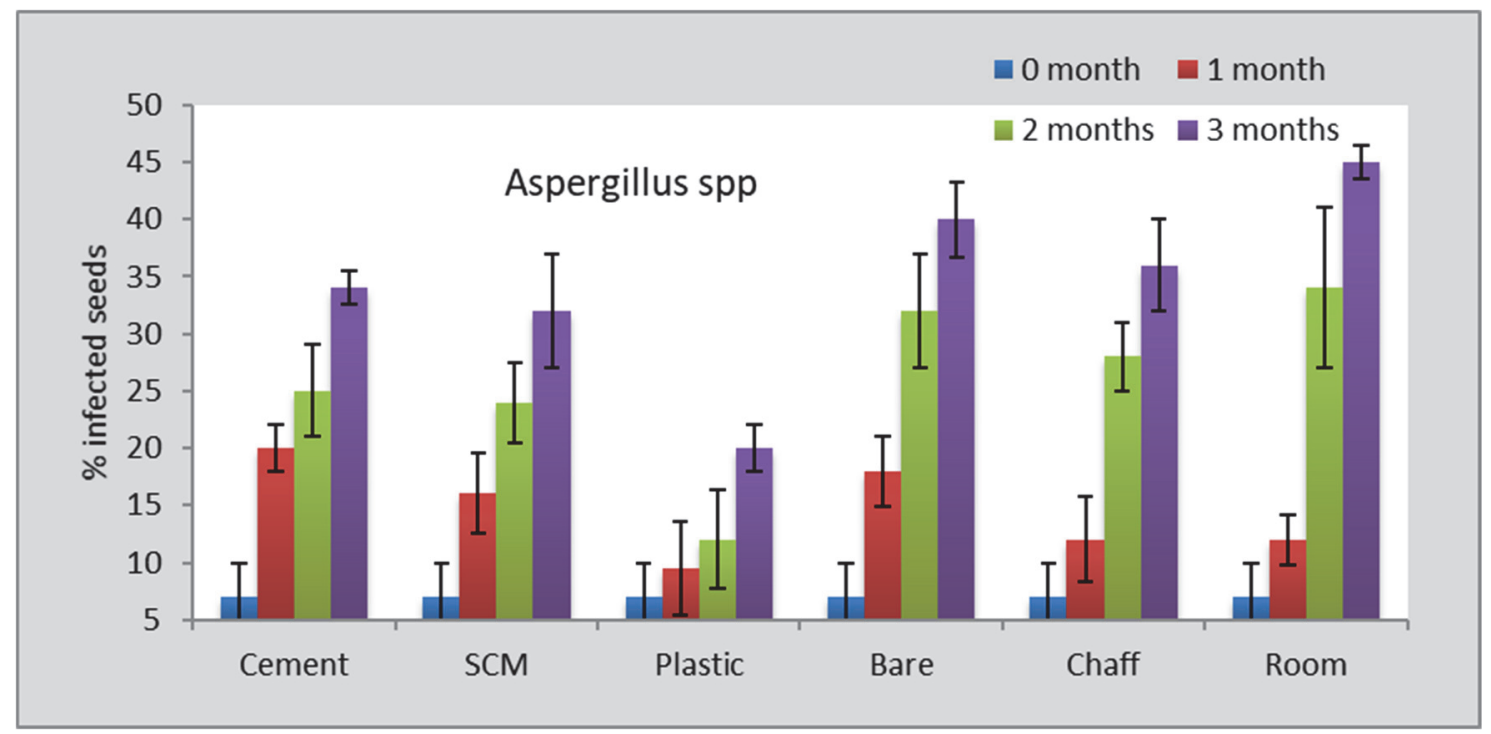

Figure 4. Aspergillus spp. change in sorghum grain stored in underground storage with different lining materials (cement, room storage, chaff, bare, plastic and straw: cow dung: mud (SCM) mix) for over three months (Values are mean $\pm \mathrm{SE}$ )

\section{Conclusion}

A comparative study of underground pit storage with different lining materials were performed to evaluate sorghum grain quality such as moisture content, 1000 kernel weight, germination capacity and fungi infestation (Aspergillus spp.). Results of this comparative study showed that, among all linings, plastic lining pit storage was a good barrier in preventing the ingression of moisture to the grain. The germination capacity of plastic lining, cement lining, room storage, chaff lining, bare and cow dung: mud: straw mixture lining at the end of the storage were $67.5 \%, 33 \%, 21 \%, 10 \%, 9 \%$ and $6 \%$, respectively. Germination capacity was high under plastic lining as compared to the others. The rate of weight loss with pit linings of cement and plastic was also low but very high for other lining materials. Rate of infection was very high in all linings except for plastic and cement lining material. Room and bare underground storage techniques were the most worst where percentages of infected seeds reach up to $45 \%$ at the end of the third month. In general, plastic lining showed a good performance in maintaining the quality of stored sorghum grain compared to the others. Hence, the farmers are beneficial if they prefer plastic linings as it provides better keeping potential than the others.

\section{Acknowledgement}

The authors thank Haramaya University for use of facilities and funding this research. The authors also thank editor-in-chief, the editorial board and an anonymous reviewer for their assistance. This study was funded fully by the Haramaya University through research grant office.

\section{References}

Abdullah, N., Nawawi, A., \& Othman, I. (2000). Fungal spoilage of starch-based foodsin relation to its water activity (aw). Journal of Stored Products Research, 36(1), 47-54.

Aboagye, D., Darko, J. O., \& Banadda, N. (2017). Comparative study of hermetic and non-hermetic storage on quality of cowpea in Ghana. Chem. Biol. Technol. Agric4: 10. https://doi.org/10.1186/s40538-017-0091-y

Agnieszka, K., \& Krzysztof, G. (2013). Criteria of Determination of Safe Grain Storage Time. A Review, Advances in Agrophysical Research. Retrieved from https://www.intechopen.com/books/advances-in-agrophysicalresearch.

AOAC. (1995). Official Methods of Analysis (16th Ed.). Association of Official Analytical Chemists, Washington, DC.

Black, M. (1970). Seed germination and dormancy. Science Progress, 58, 379-393.

Dejene, M. (2004). Grain storage methods and their effects on sorghum grain quality in Hararghe, Ethiopia. Doctoral Thesis, Swedish University of Agricultural Sciences, Uppsala, Sweden. Retrieved from 
http://pub.epsilon.slu

Dorn, Thomas W., \& Jackson-Ziems, Tamra A. (2013). Grain Storage Management to Minimize Mold and Mycotoxins. Papers inPlant Pathology. 538. Retrieved from http://digitalcommons.unl.edu/ plantpathpapers $/ 538$

Fleurat, L. F. (2002). Review on thequalitative reasoning and integrated management of the quality of stored grain: a promising new approach. Journal of Stored Products Research, 38(3), 191-218.

Laca, A., Mousia, Z., Diaz, M., Webb, C., \& Pandiella, S. S. (2006). Distribution of microbialcontamination within cereal grains. Journal of Food Engineering, 72(4), 332-338.

McGuire, S. (2005). Getting genes: rethinking seed system analysis and reform for sorghum in Ethiopia. Doctoral Thesis, Wageningen University. The Netherlands. Retrieved from http://edepot.wur.nl/121643

Proctor, D. L., \& Rowley, J. Q. (1983). The thousand grain mass (TGM): A basis for better assessment of weight losses in stored grain. Tropical Stored Products Information, 45, 1923.

Qaisrani, R. (2000). Safe storage of cereals at higher moisture levels. As in Ahmed and Alama, (2010) Research report, CSIRO, Stored Grain Research Laboratory, Kangaroo Island, S.A. Pp 5.

Rickman, J. F., \& Aquino, E. (2004). Appropriate technology for maintaining grain quality in small-scale storages. In Donahaye, E. J., Navarro, S., Bell, C., Jayas, D., Noyes, R., \& Phillips, T.W. (Eds.), Proceeding of International Conference on Controlled Atmosphere.

Sawant, A. A., Patil, S. C., Kalse, S. B., \& Thakor, N. J. (2012). Effect of temperature, relative humidity and moisture content on germination percentage of wheat stored in different storage. CIGR Journal, 14(2), 1-13.

Sisman, C. B., \& Ergin, A. S. (2011). The effects of different storage building on wheat quality. Journal of Applied Sciences, 11(14), 2613-2619.

Weinberg, Z. G., Yan, Y., Chen, Y., Finkelman, S., Ashbell, G., \& Navarro, S. (2008). The effect of moisture level on high-moisture maize (Zea mays L.) under hermetic storageconditions - in vitro studies. Journal of Stored Products Research, 44(2), 136-144, ISSN 0260-8774.

\section{Copyrights}

Copyright for this article is retained by the author(s), with first publication rights granted to the journal.

This is an open-access article distributed under the terms and conditions of the Creative Commons Attribution license (http://creativecommons.org/licenses/by/4.0/). 